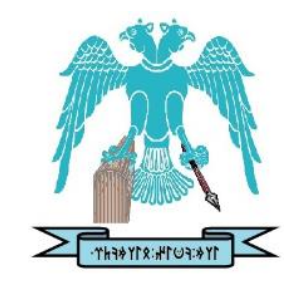

JOURNAL OF ENERGY SYSTEMS

2022, 6(1)

\title{
Performance of a combined power and cooling system under solar, solar storage and storage mode of operations
}

\author{
Tapan Kumar Gogoi \\ Tezpur University, Tezpur, India, tapan_g@tezu.ernet.in \\ Utpal Kumar Dutta (1) \\ Tezpur University, Tezpur, India, ukdutta123@gmail.com
}

\begin{abstract}
In this study, the performances of a combined power and cooling system are compared at solar, solar storage (SS), and storage mode of operations using therminol-LT (TLT) and solar salt as storage media. In the solar mode, the entire water heated in a collector field is used to drive subsequently an organic Rankine cycle and an absorption cooling system. In the SS mode during high radiation $\left(950 \mathrm{~W} / \mathrm{m}^{2}\right)$, thermal energy storage (TES) is used to store a fraction of hot water for later use during the storage mode at nighttime. The system produced $1.1 \mathrm{MW}$ of power and 2.455 MW of cooling during the solar mode at low radiation $\left(640 \mathrm{~W} / \mathrm{m}^{2}\right)$. At the SS mode, with TLT as a storage fluid, the power increased to double, however the cooling reduced by $12.22 \%$. During the storage mode, the TLT based system produced $0.553 \mathrm{MW}$ of cooling. During the SS mode with solar salt, the power and cooling increased, however, the nighttime cooling reduced significantly with solar salt. The total energy and the overall system efficiency was more with solar salt compared to those of TLT. The energy output and the system efficiency were the maximum at $950 \mathrm{~W} / \mathrm{m}^{2}$ without TES.
\end{abstract}

Keywords: Combined power and cooling, Solar absorption cooling system, Performance, Organic rankine cycle

Cite this paper as:
Gogoi, T.K., \& Dutta, U.K., Performance of a combined power and cooling system under solar, solar storage and storage mode of operations. Journal of Energy Systems 2022; 6(1): 18-32, DOI: $10.30521 /$ jes.952032 


\section{INTRODUCTION}

Solar is a clean, non-polluting and abundantly available energy source. Solar-based power and cooling technologies are used in many industrial applications. Multi-generation systems are quite promising for solar energy utilization. The combined power, cooling and heating systems may be the right candidates for solar energy use. Solar thermal power plants with energy storage provision cater to the variation in energy demand more appropriately and they are cheap compared to the non-storage type plants. In solar thermal power plants, parabolic trough solar collectors (PTSCs) are used to trap the solar heat. In the PTSC, the heat gained by a heat transfer fluid (HTF) is transferred to water in a heat recovery vapor generator (HRVG) for power generation in a steam turbine. The organic Rankine cycle (ORC) is also another technology that can be used for solar power generation. Solar driven ORCs have been proposed in many research studies. Jing et al. [1] evaluated the performance of an ORC, integrated with a low temperature PTSC at six different locations where they found higher efficiency for two-stage solar collectors over single-stage collectors. Prabhu [2] examined the economic feasibility of PTSC combined ORC for power and cooling at different locations. Delgado-Torres and Garcia-Rodriguez [3] analyzed a solar hybrid ORC to minimize the aperture area of four different types of solar collectors with a dozen of organic fluids. Bellos and Tzivanidis [4] examined the working of a solar driven ORC with four organic fluids where they found maximum ORC power with toluene followed by the power obtained from Cyclohexane, MDM and n-pentane as working fluids. Solar cooling is also gaining significant research interest. Assilzadeh et al. [5] simulated a solar ACS designed for Malaysia's climatic conditions. Liu and Wang [6] presented a double effect water-LiBr ACS where they used a storage tank for storing the hot water heated in the PTSC, which was later used as heat source for driving the lowpressure generator of the double effect ACS. Li et al. [7] analyzed a solar heat driven double effect ACS to evaluate its performance at various collector temperatures and they used the meteorological data of Guangzhaou province of China in the simulation.

Analysis of solar driven combined ORC and ACS has also been the research subject at recent times. AlSulaiman et al. [8] analyzed the performance of a solar PTSC based ORC, integrated with a single effect ACS at the solar, solar storage (SS) and storage mode of operations. They used Therminol-66 both as HTF and storage fluid while $n$-octane was the ORC working fluid. Marin et al. [9] analyzed a solar operated ORC combined with a single effect ACS where they considered R245fa and water- $\mathrm{LiBr}$ as working fluids in the ORC and ACS respectively. Eisavi et al. [10] performed thermodynamic analysis of a solar integrated multi-generation system fitted with a PTSC field, an ORC, a double effect ACS and heat exchangers in its system configuration. They used Therminol-66 as HTF in the PTSC and determined the overall system efficiency for all the year months. They also compared the performance of the proposed system by replacing the double effect ACS of the proposed system with a single effect one. Zhao et al. [11] considered one sequential and two parallel solar hybrid combined ORC and ACS configurations for comparison. They used thermal oil as HTF in the PTSC and in the sequential arrangement; the entire hot oil was used to drive the ORC and the condensing vapour in the ORC condenser was the heat source for the ACS (single effect) generator. In one parallel system, the hot oil was used to drive subsequently the ORC and the ACS one after the other while in the other, the hot oil was divided into two streams; one stream was used as the heat source for the ORC and the other stream was used for heating water to be used as a heat source for the ACS generator. Sharifishourabi and Chadegani [12] evaluated the performance of a solar based ORC combined with a triple effect ACS where they used molten salt $\left(\mathrm{NaCl}-\mathrm{MgCl}_{2}\right)$ as $\mathrm{HTF}$ in the PTSC and n-octane as ORC working fluid. Gogoi and Saikia [13] carried out thermodynamic analysis of a solar system integrated with an ORC and a water- $\mathrm{LiCl}$ operated single effect ACS. They considered R245fa, R245ca, iso-pentane, neopentane, and butane as ORC working fluids for comparison of system performance. Cioccolanti et al. [14] provided life cycle assessment of a solar-based tri-generation system comprising of a PTSC field, a diathermic oil storage tank, an ORC and an absorption chiller. They conducted a sensitivity analysis of the plant's environmental and energy performance by adjusting the system design and operating 
parameters, the size of the solar field and the working fluid of the ORC. Wang and $\mathrm{Fu} \mathrm{[15]} \mathrm{performed}$ case study of a solar assisted absorption chiller and a prime mover coupled with an ORC based power system to evaluate the system performance during typical summer and winter days. In their proposed system, they made the provision for storing hot water in thermal energy storage (TES) which was later used for driving the absorption chiller and heating purpose. The stored thermal energy from TES was also recovered by the ORC to produce extra electricity during peak load hours. Gogoi and Hazarika [16] provided comparative assessment of four novel solar based combined power and cooling (CPC) systems considering different schematic arrangements with (i) either two units of triple effect ACSs or alternately with one triple effect ACS and one ORC (ORC-I) on either side as topping cycles and (ii) either an ORC (ORC-II) or a KC as bottoming cycle. For the topping ORC (ORC-I), iso-pentane was the working fluid while for the bottoming ORC (ORC-II), R245fa was selected.

From the brief review of previous research articles, it was seen that many solar integrated power, cooling, and CPC systems have been proposed and analyzed. The energy, in the form of power and cooling, produced by any solar hybrid CPC system is subject to vary with the system configuration and the operating conditions maintained in the system. It was also observed that in some proposed systems, the solar energy was directly utilized without any provision for energy storage while in some other systems; the TES was used to harvest the solar energy. The performance of a solar hybrid power/cooling/CPC system may also vary depending on its system configuration whether it is configured with or without the TES. In some previous studies, although TES was incorporated in the system configurations but in most of cases (except in a few), it was a single storage tank where the hot fluid from the TES was used as a heat source for driving the ORC or the ACS or both, either in sequential or parallel arrangements. Moreover, majority of these systems were considered to operate mostly during the daytime periods when the solar energy is available. Even in the solar power/cooling/CPC systems where two storage tanks were used, say for example in Ref. [14], there also, the system performance was investigated mainly during the day periods with available solar radiation. Only in Ref. [8], the nighttime performance of a solar-based tri-generation system was reported in the storage mode along with the performance during the low and high radiation time in the direct solar and the SS mode of operations. The article in Ref. [15] also speaks a little about releasing stored energy during the night to improve the performance of the proposed system. In the present study, a solar-based CPC system similar to the one presented in Ref. [13] is thermodynamically analyzed, under the solar, SS, and storage mode of operations. Unlike in [13], here in the present schematic, two storage tanks are used where, Therminol-LT (TLT) is used as a storage fluid first to evaluate the system performance in the SS and storage mode of operations. Next, to provide a comparative system performance analysis in the SS and storage mode of operations, another storage medium is considered in place of TLT, which is a molten salt (solar salt, $60 \% \mathrm{NaNO}_{3}, 40 \% \mathrm{KNO}_{3}$ ). Additionally, in this study, the system operation in the direct solar mode is also considered for evaluating system performance during high sunshine period (high solar radiation) without thermal energy storage. This is done with the objective of comparing the system performance at high solar radiation time with and without the storage tanks supposing no energy requirement during nighttime.

\section{SYSTEM DESCRIPTION}

Fig. 1 shows the PTSC based combined ORC and the ACS. A single PTSC element has a parabolic trough with an absorber tube surrounded by a glass envelope, which is supported with a number of brackets. In a single row, ten PTSC elements are used in a series configuration and fifty rows of such collectors are considered. The ORC has its usual components such as heat recovery vapour generator (HRVG), the vapour turbine (VT), condenser and regenerator. Similarly, the ACS is a single effect type with one generator and other as usual components. The HTF (water) heated in the PTSC is used as the heat source for driving the ORC and the ACS. The system operates at three different modes viz. solar, SS, and storage modes. During low sunshine period in the morning and late afternoon, the entire HTF is used as a heat source for driving the ORC and subsequently the ACS (solar mode). During daytime, 
when the solar radiation intensity is high, a part of the hot HTF is used to heat the storage fluid in a heat exchanger for harvesting the solar energy in the hot storage tank (HST) while the remaining HTF drives the ORC and the ACS (SS mode). After sunset, when no solar radiation is available, the storage fluid from the HST flows to the cold storage tank (CST) for driving the ACS generator (storage mode). As such, in the storage mode, only cooling is produced by operating the ACS with hot storage fluid (either TLT or solar salt).

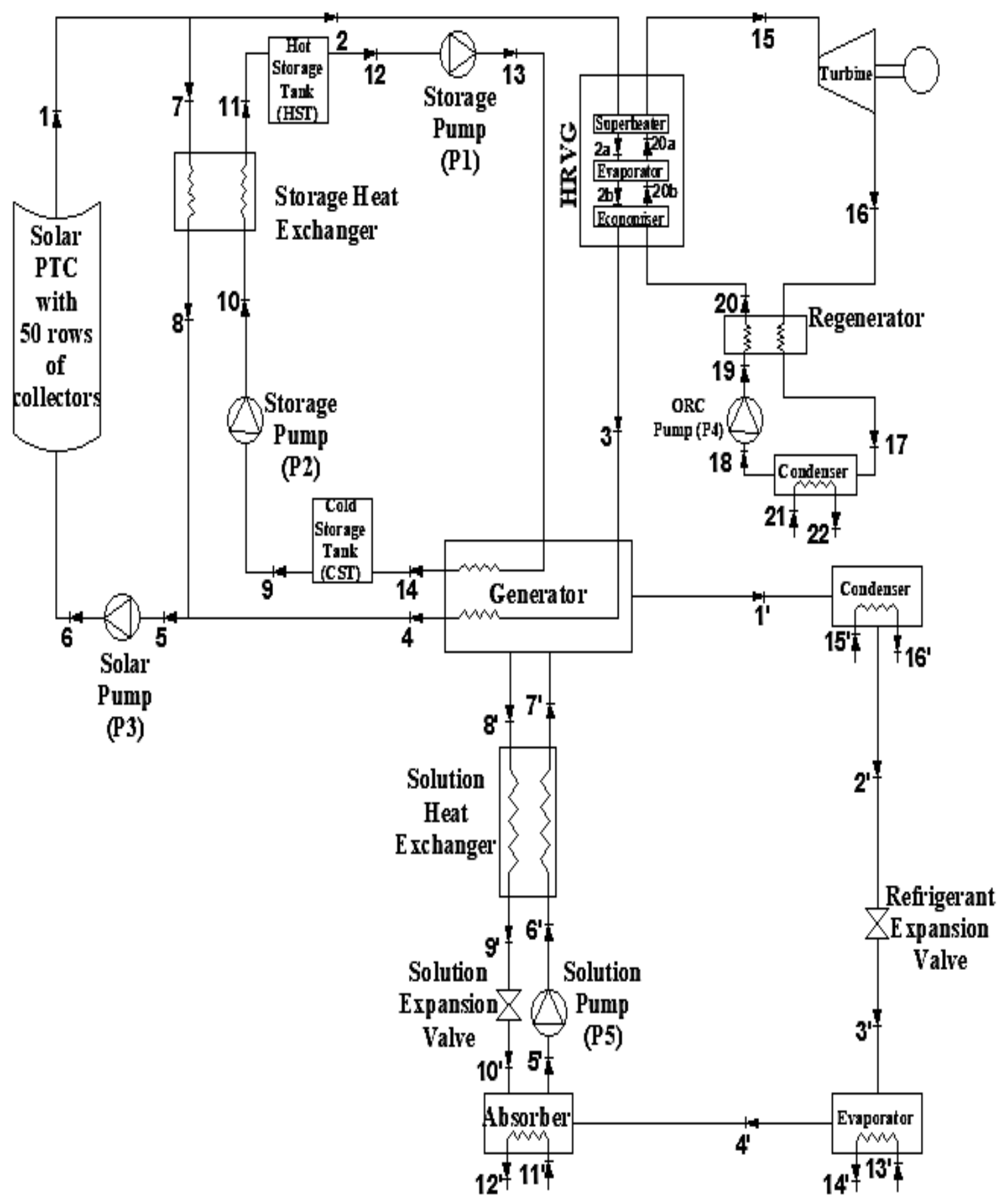

Figure 1. Schematic of the solar based CPC system. 


\section{SYSTEM MODELLING AND ASSUMPTIONS}

It is assumed that the system operation is steady. Pressure loss in the pipelines and heat loss between the system and surroundings are neglected. Water is used as HTF in the PTSC with $90{ }^{\circ} \mathrm{C}$ temperature at PTSC inlet. The solar radiation intensity $\left(I_{\text {solar }}\right)$ for the solar mode of operation during the low sunshine period (say from 6 to 8 am in the morning and 4 to $6 \mathrm{pm}$ in the evening) is taken as $640 \mathrm{~W} / \mathrm{m}^{2}$. Similarly, the time duration for the SS mode of operation is considered from 8 am in the morning to 4 $\mathrm{pm}$ in the evening and for this time, the representative solar radiation is taken as $950 \mathrm{~W} / \mathrm{m}^{2}$. The assumed geometrical and optical parameters of the PTSC are the same with those of Ref. [13]. In the ORC, isopentane is considered as the working fluid and other ORC model input parameters are taken from Ref. [13]. In the ACS, as usual assumptions are made similar to those presented in Ref. [17] except the generator temperature, which is taken as $75^{\circ} \mathrm{C}$ here. The PTSC modelling involves calculation of HTF temperature at PTSC outlet against known values of solar radiation intensity, HTF flow rate and temperature at PTSC inlet. This is done with the help of optical and thermal models. The details regarding the PTSC model are available in Ref. [13]. In fact, in Ref. [13], the model equations of Forristal [18] were only used and in Ref. [18], all the details regarding PTSC model equations, the optical and geometrical parameters, model verification etc. are described in full. The hot and cold storage tanks are modeled mostly in line with the model equations presented in Ref. [8]. The temperature of storage fluid (TLT/solar salt) at state $11\left(T_{11}\right)$ is considered $25^{\circ} \mathrm{C}$ less than the hot water temperature at state $7\left(T_{7}\right)$. The tank heat loss coefficient is taken as $0.1 \mathrm{~W} / \mathrm{m}^{2} \mathrm{~K}$ for both the HST and CST. The storage fluid temperature in the HST and CST $\left(T_{H S T}\right.$ and $\left.T_{C S T}\right)$ are calculated iteratively. The storage fluid properties at state points 9-14 are calculated using standard equations $[19,20]$. The thermo physical property relations for solar salt, which are actually valid for high temperature range, are used with an assumption that the same relations would hold true for the given temperature range with some level $( \pm 10 \%)$ of accuracy [20].

At state 14, the storage fluid temperature is assumed as $92.4{ }^{\circ} \mathrm{C}$. The HST and CST dimensions are calculated assuming equal length and diameter. The temperature at state 8 is assumed $20^{\circ} \mathrm{C}$ more than the temperature at state 10 and accordingly, from heat balance in the storage heat exchanger, the mass flow rate of hot water passing through the storage heat exchanger is calculated. The thermodynamic properties of iso-pentane at different state points of the ORC are calculated using the REFPROP 9.0 library. Mass and steady flow energy equations are employed for calculating the energy transfer terms. The temperature difference between hot water at ORC inlet and iso-pentane at VT inlet is assumed 30 ${ }^{\circ} \mathrm{C}$. Similarly, the saturation temperature of iso-pentane in the ORC is assumed $46{ }^{\circ} \mathrm{C}$ less than the VT inlet temperature in the direct solar mode at $I_{\text {solar }}=640 \mathrm{~W} / \mathrm{m}^{2}$. However, for the SS mode of operation and for the direct solar mode at $I_{\text {solar }}=950 \mathrm{~W} / \mathrm{m}^{2}$, this degree of superheat is taken as $27^{\circ} \mathrm{C}$. A pinch point temperature difference (PPTD) of $20^{\circ} \mathrm{C}$ is assumed between hot water at state point $2 \mathrm{~b}$ and isopentane at state $20 \mathrm{~b}$. Accordingly, the organic fluid mass flow rate is calculated. Net ORC powers for the solar and SS mode of operations are calculated using Eq. (1) and Eq. (2) respectively. The ORC efficiency is calculated using Eq. (3).

$$
\begin{gathered}
\text { Power }_{\text {net }, \text { solar }}=\dot{m}_{O R C}\left[\left(h_{15}-h_{16}\right) \eta_{V T}-\frac{\left(h_{19}-h_{18}\right)}{\eta_{P}}\right]-\dot{W}_{P 3} \\
\text { Power }_{\text {net }, S S}=\dot{m}_{O R C}\left[\left(h_{15}-h_{16}\right) \eta_{V T}-\frac{\left(h_{19}-h_{18}\right)}{\eta_{P}}\right]-\left(\dot{W}_{P 2}+\dot{W}_{P 3}\right) \\
\eta_{O R C}=\frac{\text { Power }_{\text {net }}}{\dot{m}_{O R C}\left(h_{15}-h_{20}\right)}
\end{gathered}
$$

In Eqs. (1) and (2), $\eta_{V T}$ and $\eta_{P}$ are the VT and pump efficiencies. $\dot{W}_{P 2}$ and $\dot{W}_{P 3}$ are the pumping powers consumed by the pumps $\mathrm{P} 2$ and $\mathrm{P} 3$ respectively. The pumping power required for running the solution pump (SP) of the ACS is very small and thus, it can be neglected. Properties of water- $\mathrm{LiBr}$, used in the ACS, are determined from the equations given in Ref. [21]. Water and steam properties are computed from IAPWS formulation 1997 [22]. The procedure described in Refs. [16,17] is only used for iterative 
calculation of the ACS cooling capacity $\left(\dot{Q}_{E}\right)$. The coefficient of performance (COP) of the ACS is defined as usually. The overall system energy efficiency is given by,

$$
\eta_{C P C}=\frac{\text { Power }_{\text {net }}+\dot{Q}_{E}}{I_{\text {solar }} A_{a} N_{\text {row }}}
$$

where, $A_{a}$ is the aperture area of the PTSC and $N_{\text {row }}$ is the number of rows of collectors in the PTSC field.

\section{MODEL VALIDATION}

One of the key concerns in any system simulation study is the accurate modeling and calculation of working fluid properties used in different systems. The accuracy of the presented results (pressure, temperature, enthalpy, mass flow rate, power, cooling, and efficiency, etc.) is established if the adopted modeling approach is correct and foolproof from every aspect. The model accuracy is usually checked by comparing the obtained results either with experimental or previously published simulation based result. In this regard, it can be mentioned that the PTSC and ORC thermal models which are used in the present study are the same with those already presented and validated in Ref. [13]. Similarly, the ACS model, which is implemented in this study by using water- $\mathrm{LiBr}$ as working solution pair, is the one that was described in detail in Ref. [17] including the ACS model validation. Therefore, the model validation of the presented systems is not repeated again in this paper.

\section{RESULTS AND DISCUSSION}

The performance of the solar operated combined cogeneration system is first evaluated for the direct solar mode of operation corresponding to low sunshine period of the morning and evening time $\left(I_{\text {solar }}=640 \mathrm{~W} / \mathrm{m}^{2}\right)$. This is followed by system performance evaluation during high sunshine period $\left(I_{\text {solar }}=950 \mathrm{~W} / \mathrm{m}^{2}\right)$ under the SS and storage mode of operations first with TLT and then with solar salt as storage fluids. These two storage fluids have no effect on the system operation during the direct solar mode of operation in which the hot HTF at PTSC outlet is used directly for driving the ORC and ACS simultaneously one after the other. The system performance in terms of power and cooling output is also evaluated during high sunshine period $\left(I_{\text {solar }}=950 \mathrm{~W} / \mathrm{m}^{2}\right)$ but without the storage system in order to assess system performance in the direct solar mode of operation. The comparative performance analysis is provided in the following sections.

\subsection{System Performance under Solar, SS and Storage Modes of Operation with TLT as Storage Fluid}

During low sunshine period $\left(I_{\text {solar }}=640 \mathrm{~W} / \mathrm{m}^{2}\right)$ under the solar mode of operation, the HTF, with a flow rate of $26.542 \mathrm{~kg} / \mathrm{s}$, could be heated in the PTSC to $184.98{ }^{\circ} \mathrm{C}$ while in the SS mode ( $I_{\text {solar }}=$ $\left.950 \mathrm{~W} / \mathrm{m}^{2}\right)$ with TLT as a storage fluid, the HTF flow rate is little less $(24.512 \mathrm{~kg} / \mathrm{s})$ and its temperature at PTSC outlet is $243.93{ }^{\circ} \mathrm{C}$. The state wise thermodynamic properties and mass flow rates that are crucial for the system performance under a given set of operating conditions for each operational mode (storage fluid: TLT) are shown in Table 1 and Table 2. As can be seen, with the change in HTF flow rate and solar radiation in the solar and SS mode of operations, the HTF temperature at PTSC outlet were changing and higher temperature was obtained in the SS mode of operations. In the solar mode, with the chosen operating parameters listed in Table 1, 1.1 MW of net power and 2.45 MW of cooling could be obtained respectively from the ORC and the ACS (refer to Table 3). Thus, the total energy output was 3.55 MW and an overall system efficiency of $16.2 \%$ was found in the solar mode. In the SS mode, since the hot water temperature is more at PTSC outlet (refer to Table 1), therefore, more vapour 
could be generated in the ORC $(22.941 \mathrm{~kg} / \mathrm{s})$ against $17.56 \mathrm{~kg} / \mathrm{s}$ associated with the solar mode of operation. Although, less amount of hot water was passing through the HRVG of the ORC in the SS mode, but due to increased hot water temperature, it was possible to maintain high VT inlet temperature in the ORC. One can see the change in property values at all salient points of the ORC (15 to 20,20a, $20 \mathrm{~b}$ ) at the solar and SS mode of operations in Table 1. Due to change in the property values and due to higher mass flow rate, the ORC in the SS mode produced a net power of $2.256 \mathrm{MW}$ (almost double) against 1.1 MW associated with the solar mode.

Table 1. State properties and mass flow rates at solar and SS modes of operation (storage fluid: TLT).

\begin{tabular}{ccccc|cccc}
\hline \multirow{2}{*}{ States } & \multicolumn{4}{c}{ Solar mode } & \multicolumn{4}{c}{ SS mode (storage fluid: TLT) } \\
\cline { 2 - 8 } & $\mathrm{P}(\mathrm{kPa})$ & $\mathrm{T}\left({ }^{\circ} \mathrm{C}\right)$ & $\dot{\mathrm{m}}(\mathrm{kg} / \mathrm{s})$ & $\mathrm{h}(\mathrm{kJ} / \mathrm{kg})$ & $\mathrm{P}(\mathrm{kPa})$ & $\mathrm{T}\left({ }^{\circ} \mathrm{C}\right)$ & $\dot{\mathrm{m}}(\mathrm{kg} / \mathrm{s})$ & $\mathrm{h}(\mathrm{kJ} / \mathrm{kg})$ \\
\hline 1 & 1179.20 & 184.98 & 26.542 & 785.14 & 3763.50 & 243.93 & 24.51 & 1056.40 \\
2 & 1179.20 & 184.98 & 26.542 & 785.14 & 3763.50 & 243.93 & 19.91 & 1056.40 \\
3 & 1120.20 & 119.43 & 26.542 & 501.40 & 3575.30 & 127.23 & 19.91 & 534.59 \\
4 & 1064.20 & 89.95 & 26.542 & 377.59 & 3396.50 & 92.4 & 19.91 & 389.69 \\
5 & 1064.20 & 89.95 & 26.542 & 377.59 & 3396.50 & 89.95 & 24.51 & 379.34 \\
6 & 1325.10 & 90.04 & 26.542 & 378.13 & 4166.50 & 90.09 & 24.51 & 380.55 \\
7 & - & - & - & - & 3763.50 & 243.93 & 4.60 & 1083.70 \\
8 & - & - & - & - & 3575.30 & 79.21 & 4.60 & 334.52 \\
9 & - & - & - & - & 52.45 & 59.21 & 6.00 & 650.630 \\
10 & - & - & - & - & 55.08 & 59.21 & 6.00 & 650.633 \\
11 & - & - & - & - & 52.32 & 218.93 & 6.00 & 1224.80 \\
15 & 872.18 & 154.98 & 17.56 & 576.89 & 3363.95 & 213.92 & 22.941 & 660.789 \\
16 & 109.16 & 113.15 & 17.56 & 504.45 & 109.17 & 130.37 & 22.941 & 540.859 \\
17 & 872.18 & 51.10 & 17.56 & 383.89 & 3363.95 & 56.41 & 22.941 & 393.580 \\
18 & 109.16 & 30 & 17.56 & 4.99 & 109.16 & 30 & 22.941 & 4.993 \\
19 & 872.18 & 30.42 & 17.56 & 6.55 & 3363.95 & 31.75 & 22.941 & 11.665 \\
20 & 872.18 & 86.46 & 17.56 & 144.44 & 3363.95 & 101.10 & 22.941 & 184.112 \\
$20 \mathrm{a}$ & 872.18 & 108.98 & 17.56 & 205.88 & 3363.95 & 186.93 & 22.941 & 487.10 \\
$20 \mathrm{~b}$ & 872.18 & 108.98 & 17.56 & 469.44 & 3363.95 & 186.93 & 22.941 & 520.36 \\
$1^{\prime}$ & 0.0563 & 75 & 1.04 & 2640.81 & 0.0563 & 75 & 0.91 & 2640.81 \\
$2^{\prime}$ & 0.0563 & 35 & 1.04 & 146.65 & 0.0563 & 35 & 0.91 & 146.65 \\
$3^{\prime}$ & 0.0087 & 5 & 1.04 & 146.65 & 0.0087 & 5 & 0.91 & 146.65 \\
$4^{\prime}$ & 0.0087 & 5 & 1.04 & 2510.07 & 0.0087 & 5 & 0.91 & 2510.07 \\
$5^{\prime}$ & 0.0087 & 35 & 22.30 & 85.37 & 0.0087 & 35 & 19.58 & 85.37 \\
$6^{\prime}$ & 0.0563 & 35 & 22.30 & 85.37 & 0.0563 & 35 & 19.58 & 85.37 \\
$7^{\prime}$ & 0.0563 & 63.49 & 22.30 & 143.40 & 0.0563 & 63.49 & 19.58 & 143.40 \\
$8^{\prime}$ & 0.0563 & 75 & 21.26 & 175.96 & 0.0563 & 75 & 18.66 & 175.96 \\
$9^{\prime}$ & 0.0563 & 45 & 21.26 & 116.71 & 0.0563 & 45 & 18.66 & 116.71 \\
$10^{\prime}$ & 0.0087 & 45 & 21.26 & 116.71 & 0.0087 & 45.00 & 18.66 & 116.71 \\
\hline & & & & & & & &
\end{tabular}

Accordingly, the ORC efficiency was also more (20.89\%) at the SS mode compared to ORC efficiency of $14.62 \%$ at the solar mode of operation. Similarly, from the ACS, $2.155 \mathrm{MW}$ of cooling was obtained in the SS mode, which is however 0.295 MW less than the cooling obtained during the solar mode (refer to Table 3). As compared to the solar mode, the hot water temperature at the ACS generator inlet was $7.8^{\circ} \mathrm{C}$ more in the SS mode. But, since the hot water mass flow rate was less, therefore, less amount of heat was supplied to the generator and this affected the ACS evaporator cooling output. But, overall the total energy output obtained from the CPC system at the SS mode of operation was more (4.411 MW) compared to $3.55 \mathrm{MW}$ that was obtained at the solar mode. Although more $(0.861 \mathrm{MW})$ total energy was obtained, but the overall system efficiency was less (13.45\%) at the SS mode. This was because a certain portion of the hot water at PTSC outlet was used to heat the oil in the storage heat exchanger that could not be utilized for direct energy generation.

In the storage mode, the temperature range of hot TLT in the HST was such that, the ORC operation was not possible and therefore, only the ACS was operated. By operating the ACS with hot TLT from the HST, only $553.49 \mathrm{KW}$ of cooling could be obtained. The property values at various states of the ACS remain invariant to the mode of operation because same component temperatures were maintained at all the three modes of operation. Only the mass flow rate of the refrigerant, weak and strong solutions are different. Refrigerant mass flow rate was the highest in the solar mode of operation $(1.04 \mathrm{~kg} / \mathrm{s})$ followed by those of the $S S(0.91 \mathrm{~kg} / \mathrm{s})$ and storage mode $(0.234 \mathrm{~kg} / \mathrm{s})$. The mass flow rates of the strong 
and weak solutions at the storage mode are 5.027 and $4.793 \mathrm{~kg} / \mathrm{s}$ respectively. This was the reason that the highest cooling was obtained during the solar mode and the minimum during the storage mode. The refrigerant mass flow rate in the ACS is subjected to change with cooling load, which was calculated iteratively. The maximum 3.286 MW of heat was supplied to the ACS generator by hot water during the solar mode of operation followed by $2.885 \mathrm{MW}$ during SS mode. During the storage mode, the hot oil from the HST could provide only $740.98 \mathrm{~kW}$ of heat to the ACS generator. Accordingly, the mass flow rates changed in the ACS and different amount of cooling was obtained at the three modes of operations.

Table 2. State properties (12-14) and mass flow rates at storage mode of operation (storage fluid: TLT).

\begin{tabular}{ccccc}
\hline States & $\mathrm{P}(\mathrm{kPa})$ & $\mathrm{t}\left({ }^{\circ} \mathrm{C}\right)$ & $\dot{\mathrm{m}}(\mathrm{kg} / \mathrm{s})$ & $\mathrm{h}(\mathrm{kJ} / \mathrm{kg})$ \\
\hline 12 & 49.27 & 145.9 & 4.00 & 946.79 \\
13 & 51.74 & 145.9 & 4.00 & 946.80 \\
14 & 49.27 & 92.4 & 4.00 & 761.55 \\
\hline
\end{tabular}

Table 3. System performance comparison under solar, SS and storage modes of operation (storage fluid: TLT).

\begin{tabular}{lccccccc}
\hline \multicolumn{1}{c}{ Modes } & $\mathrm{I}_{\text {solar }}\left(\mathrm{W} / \mathrm{m}^{2}\right)$ & Net power $(\mathrm{MW})$ & $\eta_{\text {ORC }}(\%)$ & $\dot{Q}_{E}(\mathrm{MW})$ & COP & Total energy $(\mathrm{MW})$ & $\eta_{\mathrm{CPC}}(\%)$ \\
\hline Solar & 640 & 1.1 & 14.62 & 2.455 & 0.747 & 3.555 & 16.2 \\
SS & 950 & 2.256 & 20.89 & 2.155 & 0.747 & 4.411 & $13.45 \%$ \\
Storage & - & - & - & 0.553 & 0.747 & & - \\
\hline
\end{tabular}

\subsection{Performance Comparison between TLT and Solar Salt Operated Systems under SS and Storage Modes of Operation}

In the solar storage system, when TLT is replaced with solar salt, comparatively more power is obtained from the ORC during SS mode of operation. The detailed comparison is shown in Table 4 and Fig 2.

Earlier with TLT as a storage fluid, during SS mode of operation, the mass flow rate through the ORC was $22.941 \mathrm{~kg} / \mathrm{s}$ which for solar salt increases to $26.338 \mathrm{~kg} / \mathrm{s}$. This increase in the ORC mass flow rate is responsible for the increase in the net power output from the ORC. The thermodynamic properties at various ORC states are not affected by the fluid medium in the storage system. These properties at various ORC states (15-20b) are the same with those presented in Table 1 at the right column [SS mode (storage fluid: TLT)]. Hence, these are not shown again in Table 4 and only the change in mass flow rate of the organic fluid in the ORC is reported.

Table 4. Change in thermodynamic properties and mass flow rate due to use of solar salt in place of TLT in the storage system.

\begin{tabular}{|c|c|c|c|c|c|c|c|c|}
\hline \multicolumn{5}{|c|}{ SS mode (Storage fluid: TLT) } & \multicolumn{4}{|c|}{ SS mode (Storage fluid: Solar salt) } \\
\hline States & $\mathrm{P}(\mathrm{kPa})$ & $\mathrm{T}\left({ }^{\circ} \mathrm{C}\right)$ & $\dot{\mathrm{m}}(\mathrm{kg} / \mathrm{s})$ & $\mathrm{h}(\mathrm{kJ} / \mathrm{kg})$ & $\mathrm{P}(\mathrm{kPa})$ & $\mathrm{T}\left({ }^{\circ} \mathrm{C}\right)$ & $\dot{\mathrm{m}}(\mathrm{kg} / \mathrm{s})$ & $\mathrm{h}(\mathrm{kJ} / \mathrm{kg})$ \\
\hline 1 & 3763.50 & 243.93 & 24.51 & 1056.40 & 3763.50 & 243.93 & 24.51 & 1056.40 \\
\hline 2 & 3763.50 & 243.93 & 19.91 & 1056.40 & 3763.50 & 243.93 & 22.86 & 1056.40 \\
\hline 3 & 3575.30 & 127.23 & 19.91 & 534.59 & 3575.30 & 127.23 & 22.86 & 534.59 \\
\hline 4 & 3396.50 & 92.4 & 19.91 & 389.69 & 3396.50 & 92.4 & 22.86 & 389.69 \\
\hline 5 & 3396.50 & 89.95 & 24.51 & 379.34 & 3396.50 & 99.5 & 24.51 & 419.50 \\
\hline 6 & 4166.50 & 90.09 & 24.51 & 380.55 & 4166.50 & 90.09 & 24.51 & 380.55 \\
\hline 7 & 3763.50 & 243.93 & 4.60 & 1083.70 & 3763.50 & 243.93 & 1.65 & 1083.70 \\
\hline 8 & 3575.30 & 79.21 & 4.60 & 334.52 & 3575.30 & 194.59 & 1.65 & 832.56 \\
\hline 9 & 52.45 & 59.21 & 6.00 & 650.630 & 93.35 & 174.59 & 6.00 & 659.529 \\
\hline 10 & 55.08 & 59.21 & 6.00 & 650.633 & 98.02 & 174.59 & 6.00 & 659.532 \\
\hline 11 & 52.32 & 218.93 & 6.00 & 1224.80 & 93.12 & 218.93 & 6.00 & 728.6 \\
\hline $15-20 b$ & & & 22.941 & & & & 26.338 & \\
\hline $1^{\prime}-4^{\prime}$ & & & 0.91 & & & & 1.05 & \\
\hline $5^{\prime}-7^{\prime}$ & & & 19.58 & & & & 22.47 & \\
\hline $8^{\prime}-10^{\prime}$ & & & 18.66 & & & & 21.43 & \\
\hline
\end{tabular}


Use of solar salt in the storage system also affected the HTF mass flow rate passing through the HRVG of the ORC. The mass flow rate of storage fluid passing through the storage heat exchanger from the CST to HST was fixed $6 \mathrm{~kg} / \mathrm{s}$ for both TLT and solar salt. But, the change in the storage fluid (from TLT to solar salt) reduced the HTF mass flow rate from $4.6 \mathrm{~kg} / \mathrm{s}$ to $1.65 \mathrm{~kg} / \mathrm{s}$ that was passing through the storage heat exchanger (refer to mass flow rates at state points 7 and 8 of Table 4). As can also be seen from the change in property values at state points $8-11$ of Table 4 , the thermodynamic properties (pressure, temperature and enthalpy) change with change in the storage fluid. Moreover, the heat balance in the storage heat exchanger decides the HTF mass flow rate that is required to be circulated through the heat exchanger. Since, less amount of HTF is required to satisfy the heat balance in the storage heat exchanger when solar salt is used; therefore, more HTF $(26.338 \mathrm{~kg} / \mathrm{s})$ goes to the HRVG of ORC, which in turn produces more organic vapour in the ORC and thus more ORC power output.

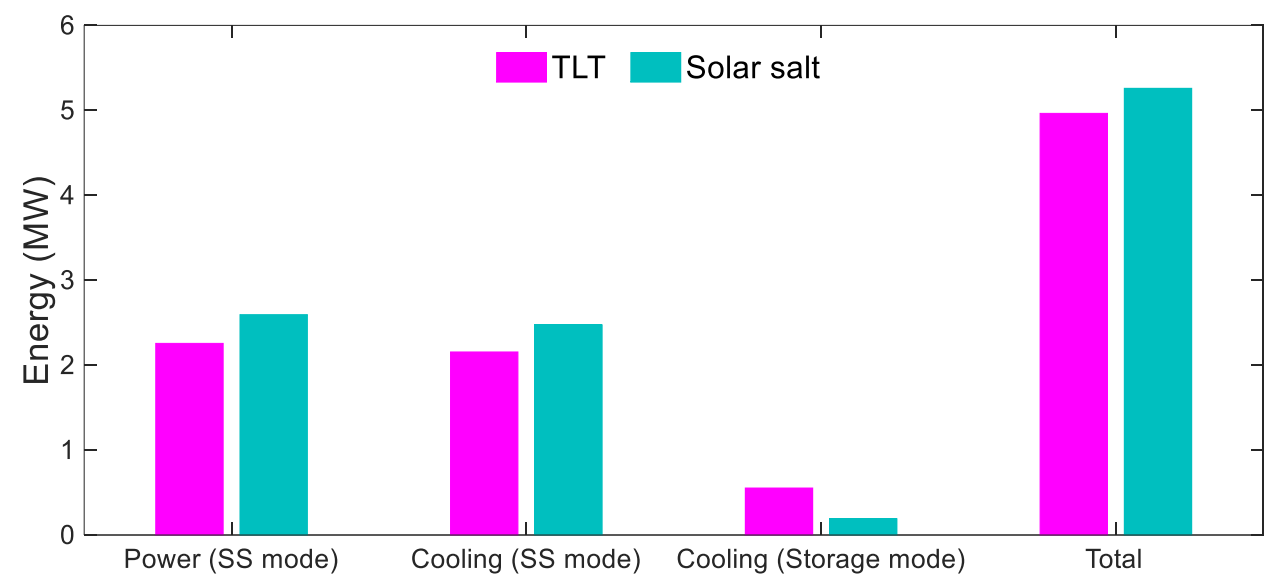

Figure 2. Comparison of power, cooling and total energy obtained from the TLT and solar salt operated systems under SS and storage modes of operation.

Cooling energy produced in the ACS evaporator during SS mode of operation is also more when solar salt is used as a storage fluid. This is also due to comparatively higher HTF mass flow rate $(26.338 \mathrm{~kg} / \mathrm{s})$ compared to $22.941 \mathrm{~kg} / \mathrm{s}$ that was passing through the ACS generator when TLT was used as a storage fluid. Consequently, more heat was supplied to the ACS generator and with fixed component temperatures maintained in the ACS for both TLT and solar salt, ultimately the water vapour which was produced in the ACS generator increases from $0.91 \mathrm{~kg} / \mathrm{s}$ that was produced earlier with TLT to $1.05 \mathrm{~kg} / \mathrm{s}$ (this is also the refrigerant flow rate) now with solar salt use. Proportionately, the mass flow rates of weak and strong solutions also change. The weak and strong solution's mass flow rates, which were earlier $18.66 \mathrm{~kg} / \mathrm{s}$ and $19.55 \mathrm{~kg} / \mathrm{s}$, increase to $21.43 \mathrm{~kg} / \mathrm{s}$ and $22.47 \mathrm{~kg} / \mathrm{s}$ respectively due to replacing TLT with solar salt. Increase in heat supply to the ACS generator and consequently the refrigerant mass flow with the use of solar salt led ultimately to production of more cooling energy in the ACS evaporator. The thermodynamic properties at various ACS states are fixed and do not change, neither with change in the mode of operation (direct solar/SS/storage) nor with the change in the storage fluid. Hence, these are not shown in Table 4 and only the change in the refrigerant, weak and strong solution mass flow rates is shown.

As opposed to SS mode, in the storage mode of operation during nighttime, the ACS produces comparatively less amount of cooling $(0.191 \mathrm{MW})$ by using the stored energy of the solar salt as a heat source. The cooling energy is in fact $65.46 \%$ less compared to what it was earlier $(0.553 \mathrm{MW})$ when TLT was used to drive the ACS generator during storage mode at nighttime. Although, less cooling was obtained during night time by using solar salt as a heat source but the total energy output of the combined cogeneration system was more (5.259 MW) when compared with 4.964 MW corresponding to TLT, if both the system produced power and cooling energies under SS and storage modes of operation are considered as a whole. This is due to the fact that, the ORC produces more power and the ACS produces more cooling during the SS mode of system operation when solar salt is used as a storage medium. In the SS mode of operation, with solar salt as a storage medium, the ORC produces a net power of 2.594 
MW as compared to a net ORC power of $2.256 \mathrm{MW}$, produced earlier with TLT as a storage medium. Similarly, when the solar salt is used, the ACS produces a cooling energy of $2.474 \mathrm{MW}$ against 2.155 MW of cooling obtained earlier with TLT as a storage medium. The total energy output of the combined cogeneration system is the sum of net ORC power produced during the SS mode of system operation and the ACS cooling energies obtained during the SS mode and the storage mode at nighttime. As such, if the demand for cooling is less during night, use of solar salt can be preferred over TLT as working fluid in the storage tanks.

Further during ACS operation in the storage mode with hot solar salt as the driving energy source, it was seen that when solar salt is used in place of TLT, again due to change in thermodynamic property values at the state points 12,13 and 14 (refer to Table 5), less amount of heat is supplied by the solar salt to the ACS generator ( $255.88 \mathrm{~kW}$ ) compared to $740.98 \mathrm{~kW}$ that was supplied earlier by TLT. This was the reason that the refrigeration flow rate also reduced to $0.081 \mathrm{~kg} / \mathrm{s}$, which was previously 0.234 $\mathrm{kg} / \mathrm{s}$ in case of TLT. Accordingly, the ACS produced cooling energy reduced with solar salt use during ACS operation at the nighttime.

The comparison of ORC and the overall efficiency of the CPC system operated with TLT and solar salt as storage fluids under SS mode of operation is shown in Fig. 3. As can be seen, the ORC efficiency does not change due to use of solar salt in place of TLT. As explained earlier, the HTF mass flow rate passing through the HRVG of the ORC changes with the change in the storage fluid and accordingly, the mass flow rate of organic fluid in the ORC also changes. Therefore, the net ORC power ( Power $_{\text {net }}$ ) and the amount of heat supplied by the hot HTF to the HRVG $\left[\dot{m}_{O R C}\left(h_{15}-h_{20}\right)\right]$ also change proportionately without causing any change in the ORC efficiency value. However, the CPC system efficiency is more because the ORC produces more net power and the ACS also generates comparatively more cooling (refer to Fig. 2) during the SS mode of system operation when the solar salt is used as storage fluid in the storage tanks. On the other hand, the solar energy input as defined in Eq. (4) remains the same irrespective of whether it is TLT or solar salt is the storage fluid. Since the total energy output of the combined cogeneration system is more with solar salt (5.259 MW) than that with TLT (4.964 MW), therefore, the CPC system efficiency becomes high for solar salt.

Table 5. Change in state (12-14) properties due to replacing TLT with solar salt during ACS operation in the storage mode.

\begin{tabular}{ccccc|cccc}
\hline & \multicolumn{4}{c}{ Storage mode (storage fluid: TLT) } & \multicolumn{3}{c}{ Storage mode (storage fluid: Solar salt) } \\
\hline States & $\mathrm{P}(\mathrm{kPa})$ & $\mathrm{t}\left({ }^{\circ} \mathrm{C}\right)$ & $\dot{\mathrm{m}}(\mathrm{kg} / \mathrm{s})$ & $\mathrm{h}(\mathrm{kJ} / \mathrm{kg})$ & $\mathrm{P}(\mathrm{kPa})$ & $\mathrm{t}\left({ }^{\circ} \mathrm{C}\right)$ & $\dot{\mathrm{m}}(\mathrm{kg} / \mathrm{s})$ & $\mathrm{h}(\mathrm{kJ} / \mathrm{kg})$ \\
\hline 12 & 49.27 & 145.9 & 4.00 & 946.79 & 94.16 & 134.23 & 4.00 & 597.25 \\
13 & 51.74 & 145.9 & 4.00 & 946.80 & 98.86 & 134.24 & 4.00 & 597.27 \\
14 & 49.27 & 92.4 & 4.00 & 761.55 & 94.16 & 92.4 & 4.00 & 533.30 \\
\hline
\end{tabular}

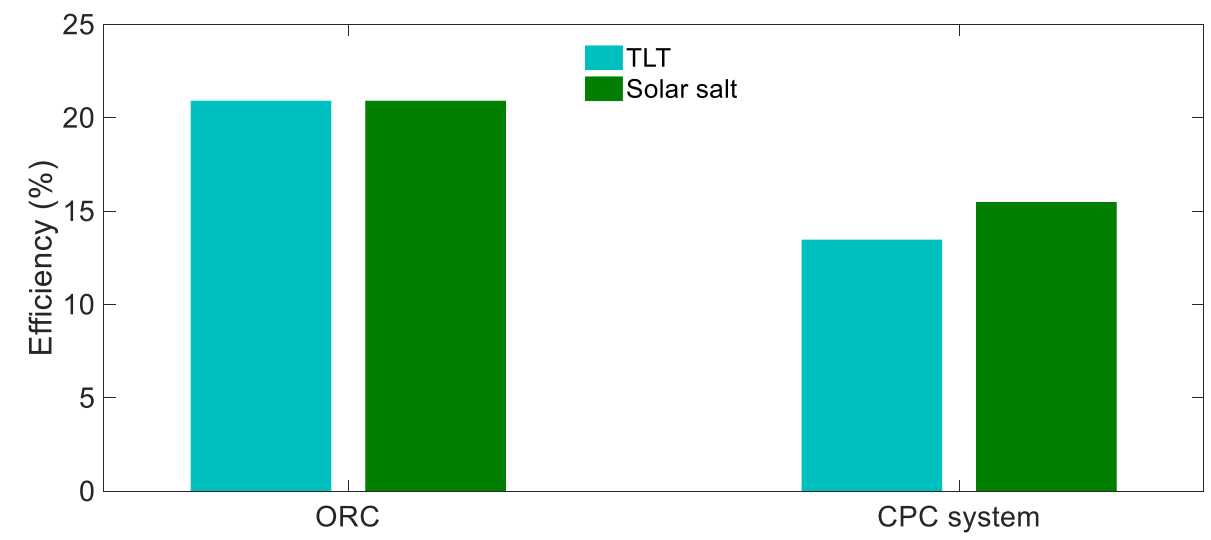

Figure 3. Comparison of ORC and CPC efficiency obtained from SS mode of system operation with TLT and solar salt as storage fluids. 


\subsection{System Performance at High Solar Radiation $\left(I_{\text {solar }}=950 \mathrm{~W} / \mathrm{m}^{2}\right)$ under Direct Solar Mode of Operation without TES and the Overall Performance Comparison}

Previously, the CPC system operation at high solar radiation $\left(I_{\text {solar }}=950 \mathrm{~W} / \mathrm{m}^{2}\right)$ was considered under SS mode of operation in order to store some amount of solar energy for using it during the nighttime for driving the ACS. In case if there is no demand for cooling energy during the night, then the solar energy is not required to be stored and hence, the necessity for the use of the storage system (hence TLT and solar salt) would not arise. Under this situation, the HTF at PTSC outlet can be used directly for driving the ORC and ACS like it was used earlier in case low solar radiation $\left(I_{\text {solar }}=\right.$ $640 \mathrm{~W} / \mathrm{m}^{2}$ ). Certainly, the system performance at $I_{\text {solar }}=950 \mathrm{~W} / \mathrm{m}^{2}$ under direct solar mode operation without the storage system would not be the same with the previous cases, analyzed and discussed in the preceding sections. In this section, the performance of the CPC system at high solar radiation $\left(I_{\text {solar }}=950 \mathrm{~W} / \mathrm{m}^{2}\right)$ under direct solar mode of operation without the energy storage is compared with the previously analyzed three cases of (i) direct solar mode $\left(I_{\text {solar }}=640 \mathrm{~W} / \mathrm{m}^{2}\right.$ ), (ii) SS mode $\left(I_{\text {solar }}=950 \mathrm{~W} / \mathrm{m}^{2}\right)$ with TLT as storage fluid and (iii) SS mode $\left(I_{\text {solar }}=950 \mathrm{~W} / \mathrm{m}^{2}\right)$ with solar salt as storage fluid.

The net ORC power, ACS produced cooling and the total energy (net power plus ACS cooling) obtained from the CPC system at $\mathrm{I}_{\text {solar }}=950 \mathrm{~W} / \mathrm{m}^{2}$ under direct solar mode of operation is shown in Fig. 4 along with those obtained previously from the other three modes of operations to provide an overall performance comparison. From the results in Fig. 4, it was observed that the net ORC power at $I_{\text {solar }}=$ $950 \mathrm{~W} / \mathrm{m}^{2}$ under direct solar mode of operation is significantly higher than the power corresponding to direct solar mode of operation at $I_{\text {solar }}=640 \mathrm{~W} / \mathrm{m}^{2}$. In fact, the net ORC power at the direct solar mode of operation at $I_{\text {solar }}=950 \mathrm{~W} / \mathrm{m}^{2}$ is also higher than those of the other two cases corresponding to SS modes of operation. The same is the case with the cooling energy obtained from the ACS and the total energy output. During the direct solar mode of operation at $I_{\text {solar }}=950 \mathrm{~W} / \mathrm{m}^{2}$, the HTF mass flow rate at PTSC outlet is the same $(24.51 \mathrm{~kg} / \mathrm{s}$ ) with those of the SS modes (TLT and solar salt based) of operations (refer to state 1 of Table 4). However, unlike in the SS modes of operation where from the total HTF flow, certain amount was routed through the storage heat exchanger but here in this mode, the entire HTF was passed through the HRVG of the ORC. As such in this mode of operation, more amount of HTF $(24.51 \mathrm{~kg} / \mathrm{s})$ flows through the HRVG compared to those $(19.91 \mathrm{~kg} / \mathrm{s}$ and $22.86 \mathrm{~kg} / \mathrm{s})$ of the two SS modes of operations. As a result, the amount of organic vapour produced in the HRVG was also the highest $(28.24 \mathrm{~kg} / \mathrm{s})$ for this case and with the ORC state properties remaining invariant for these three cases, ultimately, the highest power was obtained during this mode of system operation only. As can be seen, the highest power obtained for system operation under direct solar mode at $\mathrm{I}_{\text {solar }}=950 \mathrm{~W} / \mathrm{m}^{2}$ is not only because of change in the state properties (due to change in $I_{\text {solar }}$ from 640 to $950 \mathrm{~W} / \mathrm{m}^{2}$ but also due to higher organic fluid mass flow through the ORC. This direct solar mode of system operation at $I_{\text {solar }}=950 \mathrm{~W} / \mathrm{m}^{2}$ is identical with the other two SS modes of operation in the sense that for all these three cases, $I_{\text {solar }}=950 \mathrm{~W} / \mathrm{m}^{2}$. Otherwise, actually, the HTF mass flow rate is the highest $(26.542$ $\mathrm{kg} / \mathrm{s}$ ) for the direct solar mode at $I_{\text {solar }}=640 \mathrm{~W} / \mathrm{m}^{2}$. However due to low HTF temperature at PTSC outlet and the corresponding low enthalpy values of HTF at various states (1-6), the system generated power and cooling energy (hence the total energy) were the lowest for this case.

The same observation was made in the case of cooling energy obtained from the ACS during direct solar mode of system operation at $I_{\text {solar }}=950 \mathrm{~W} / \mathrm{m}^{2}$. Due to higher mass flow rate associated with the energy source, more amount of heat was supplied to the ACS generator and accordingly, the refrigerant flow was also the highest for this case $(1.2 \mathrm{~kg} / \mathrm{s})$ compared to $1.04 \mathrm{~kg} / \mathrm{s}, 0.91$ and $1.05 \mathrm{~kg} / \mathrm{s}$ in respect of the direct solar mode at $I_{\text {solar }}=640 \mathrm{~W} / \mathrm{m}^{2}$, TLT and solar salt based SS modes of operations. The corresponding weak and strong solution mass flow rates in the ACS for this case (direct solar $I_{\text {solar }}=$ $950 \mathrm{~W} / \mathrm{m}^{2}$ ) were $24.61 \mathrm{~kg} / \mathrm{s}$ and $25.81 \mathrm{~kg} / \mathrm{s}$ respectively. The components' operating temperatures in the ACS are fixed for all the above four cases and so are the thermodynamic properties at various states $\left(1^{\prime}-\right.$ $\left.10^{\prime}\right)$. Increase in the refrigerant mass flow rate is mainly responsible for higher cooling output from the ACS. Since the highest net ORC power and cooling were obtained during direct solar mode of system operation at $I_{\text {solar }}=950 \mathrm{~W} / \mathrm{m}^{2}$, therefore, the total energy output (sum of net ORC power and ACS 
cooling) was also the maximum (5.6252 MW) for this case. The next highest total energy output was $5.068 \mathrm{MW}$ during SS mode of system operation with solar salt as storage fluid. The total energy outputs corresponding to TLT based system operation under SS mode and direct solar mode at $I_{\text {solar }}=$ $640 \mathrm{~W} / \mathrm{m}^{2}$ are $4.411 \mathrm{MW}$ and $3.55 \mathrm{MW}$ respectively.

The ORC and CPC system efficiencies corresponding to system operation in the direct solar mode at $I_{\text {solar }}=950 \mathrm{~W} / \mathrm{m}^{2}$ are shown in Fig. 5. The results show that for this case, the ORC efficiency is the same $20.89 \%$ with those of the other two cases corresponding to SS modes of system operation with TLT and solar salt as storage fluids. The same ORC efficiency for all these cases is due to the proportionate increase in net ORC power in accordance with the amount of heat supplied to the HRVG as explained before. Since the highest total energy (power and cooling together) output of 5.6252 MW was obtained during the direct solar mode of system operation at $I_{\text {solar }}=950 \mathrm{~W} / \mathrm{m}^{2}$, therefore, the overall CPC system efficiency was also the maximum for this case followed by those of the solar salt driven SS mode of operation and TLT based SS mode of operation. This was also because of fixed solar energy input supplied during the direct solar mode of system operation at $I_{\text {solar }}=950 \mathrm{~W} / \mathrm{m}^{2}$ and SS mode of operations with TLT and solar salt as storage fluids. Only during the direct solar mode of system operation at $I_{\text {solar }}=640 \mathrm{~W} / \mathrm{m}^{2}$, the solar energy input to the system was different and it was less. For this case, the net ORC power, ACS cooling and total energy output were 1.1 MW, 2.45 MW and 3.55 MW respectively and therefore, the total energy output was also the minimum for this case. However, since the solar energy input was also correspondingly less, therefore, the CPC system efficiency changed accordingly, which was found slightly lower than that corresponding to the direct solar mode at $I_{\text {solar }}=$ $950 \mathrm{~W} / \mathrm{m}^{2}$ and higher than those of the TLT and solar salt based systems under SS mode of operation. Since earlier for the same solar energy input $\left(I_{\text {solar }}=950 \mathrm{~W} / \mathrm{m}^{2}\right)$, the lowest total energy output was found for the TLT operated system under SS mode of operation, therefore, the CPC system efficiency was also the lowest for this case.

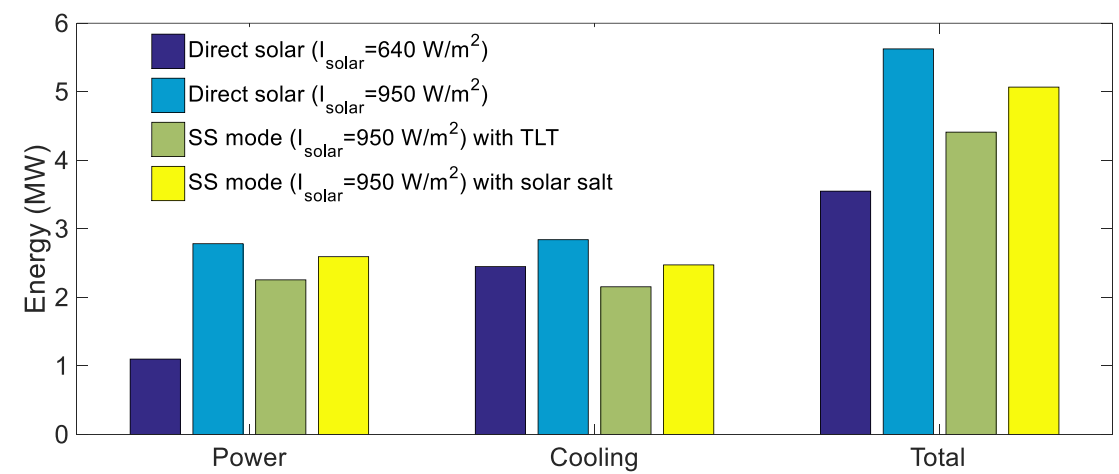

Figure 4. Comparison of power, cooling and total energy obtained from the CPC system at high solar radiation $\left(I_{\text {solar }}=950 \mathrm{~W} / \mathrm{m}^{2}\right)$ under direct solar mode without the energy storage with those corresponding to (i) direct solar mode $\left(I_{\text {solar }}=640 \mathrm{~W} / \mathrm{m}^{2}\right)$, (ii) SS mode $\left(I_{\text {solar }}=950 \mathrm{~W} / \mathrm{m}^{2}\right)$ with TLT as storage fluid and (iii) SS mode ( $I_{\text {solar }}=$ $950 \mathrm{~W} / \mathrm{m}^{2}$ ) with solar salt as storage fluid.

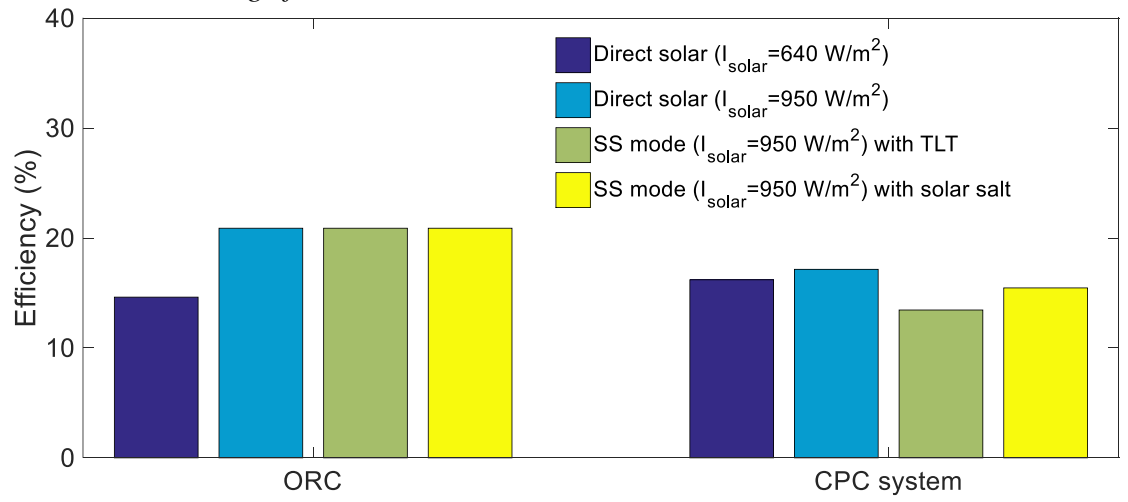

Figure 5. Comparison of ORC and CPC system efficiency at high solar radiation $\left(I_{\text {solar }}=950 \mathrm{~W} / \mathrm{m}^{2}\right)$ under direct solar mode without the energy storage with those corresponding to (i) direct solar mode $\left(I_{\text {solar }}=640 \mathrm{~W} / \mathrm{m}^{2}\right)$, (ii) SS mode $\left(I_{\text {solar }}=950 \mathrm{~W} / \mathrm{m}^{2}\right)$ with TLT as storage fluid and (iii) $S S$ mode $\left(I_{\text {solar }}=950 \mathrm{~W} / \mathrm{m}^{2}\right)$ with solar salt as storage fluid. 


\section{SUMMARY AND CONCLUSIONS}

The performance of a solar-based CPC system was evaluated in this study under the solar, SS, and storage modes of operation first with TLT and next with solar salt as storage fluid. Two solar radiation intensities $\left(I_{\text {solar }}=640\right.$ and $\left.950 \mathrm{~W} / \mathrm{m}^{2}\right)$ were considered representing low and high solar radiations. Initially, the solar intensity $\left(I_{\text {solar }}=640 \mathrm{~W} / \mathrm{m}^{2}\right)$ of the low sunshine period (morning and evening) was considered for system performance evaluation in the direct solar mode of operation. Next, by considering TES with TLT as storage fluid, the CPC system performance was evaluated for the SS mode of operation during daytime with $I_{\text {solar }}=950 \mathrm{~W} / \mathrm{m}^{2}$ and the storage mode during nighttime for providing a comparative analysis among the direct solar mode $\left(I_{\text {solar }}=640 \mathrm{~W} / \mathrm{m}^{2}\right), \mathrm{SS}$ and storage mode of operations. In the TES, next, solar salt was considered as a storage fluid to compare with the TLT based system performance under the SS and storage mode of operations. Further, in this study, the CPC system performance was assessed in the direct solar mode also, during high sunshine period $\left(I_{\text {solar }}=950 \mathrm{~W} / \mathrm{m}^{2}\right)$, for comparing energy outputs with and without TES assuming no energy requirement during nighttime. The main findings of this study are summarized as follows.

At low sunshine period $\left(I_{\text {solar }}=640 \mathrm{~W} / \mathrm{m}^{2}\right)$, the HTF in the PTSC could be heated from $90^{\circ} \mathrm{C}$ to 184.98 ${ }^{\circ} \mathrm{C}$ and using this hot water, 1.1 MW of net power and $2.455 \mathrm{MW}$ of cooling were obtained from the ORC and ACS respectively in the direct solar mode of operation.

During the SS mode of operation $\left(I_{\text {solar }}=950 \mathrm{~W} / \mathrm{m}^{2}\right)$ with TES and TLT as storage fluid, although less amount of hot water was passing through the ORC, but due to higher hot water temperature at HRVG inlet $\left(243.93{ }^{\circ} \mathrm{C}\right)$, the operating conditions in the ORC changed leading to more organic vapour generation and high net power. The ORC efficiency, at the SS mode of operation with TLT as storage fluid, was also high compared to that of the direct solar mode at $I_{\text {solar }}=640 \mathrm{~W} / \mathrm{m}^{2}$.

Further in the SS mode of operation (storage fluid: TLT), although the hot water temperature at the ACS generator inlet was $7.8^{\circ} \mathrm{C}$ more, but due to lower mass flow rate, less amount of heat was supplied and accordingly the ACS provided less cooling which was 0.295 MW less compared to that of the direct solar mode at $I_{\text {solar }}=640 \mathrm{~W} / \mathrm{m}^{2}$.

The total energy output that was obtained from the solar CPC system at the SS mode of operation with TLT as storage fluid was found to be $0.861 \mathrm{MW}$ more than that of the direct solar mode ( $I_{\text {solar }}=$ $640 \mathrm{~W} / \mathrm{m}^{2}$ ) of operation. However, the overall system efficiency was less during the SS mode of operation compared to that of the direct solar mode of operation at $I_{\text {solar }}=640 \mathrm{~W} / \mathrm{m}^{2}$.

Using the stored energy of hot TLT during the storage mode, only the ACS could be operated and 0.553 MW of cooling energy was generated.

The system performance in the SS mode of operation, in terms power, cooling and total energy output, improved with the use of solar salt over TLT although, the ACS cooling obtained during the storage mode of operation at nighttime was significantly less for solar salt $(0.191 \mathrm{MW})$ compared to that of TLT $(0.553 \mathrm{MW})$. The cooling energy, which was less for TLT in the SS mode compared to that of the direct solar mode at $I_{\text {solar }}=640 \mathrm{~W} / \mathrm{m}^{2}$, also increased to the same level (in fact $19 \mathrm{~kW}$ more) with the use of solar salt. The CPC system overall efficiency was also high in case of solar salt during the SS mode of operation.

The ORC net power, ACS cooling and total energy outputs and the overall system efficiency were the highest during the direct solar mode of operation $\left(I_{\text {solar }}=950 \mathrm{~W} / \mathrm{m}^{2}\right)$ at high sunshine period for the system without TES. However, in such a situation, no energy will be stored in the TES for later use during nighttime for cooling purposes. 
In order to produce power and cooling simultaneously during the nighttime, system operation in the hybrid mode may be considered by using some other renewable/conventional energy source based prime movers.

Thus from this study, important data regarding performance of a solar based CPC system is made available for solar, SS and storage modes of operations. The results may be useful for manufacturers dealing with the construction and installation of solar-based power and cooling systems.

\section{REFERENCES}

[1] Li, J., Pei, G., P, Jiie, J. Optimization of low temperature solar thermal electricgeneration with organic rankine cycle in different areas. Applied Energy 2010;87(11):3355-65.

[2] Prabhu E. Solar trough organic rankine electricity system (stores) stage 1: powerplant optimization andeconomics.National Renewable Energy Laboratory 2006;California, USA: NREL/SR-550-39433.

[3] Delgado-Torres, A.M., García-Rodríguez, L. Analysis and optimization of the lowtemperature solar organic rankine cycle (ORC).Energy ConversionandManagement 2010; 51:2846-2856.

[4] Bellos, E., Tzivanidis, C., Investigation of a hybrid ORC driven by waste heat and solar energy.EnergyConversion Management 2018; 156: 427-439.

[5] F. Assilzadeh, F., Kalogiro,S.A., Ali,Y., Sopian, K. Simulation and optimization of a LiBr solar absorption cooling system with evacuated tube collectors, Renewable Energy 2005;30:1143-1159.

[6] Liu, YL, Wang, R. Performance prediction of a solar/gas driving double effectLiBr-H2O absorption system.Renewable Energy2004; 29:1677-1695.

[7] Li, Z., Ye, X., Liu, J. Performance analysis of solar air cooled double effect LiBr/H2Oabsorption cooling system in subtropical city. Energy Conversion and Management 2004; 85:302-312.

[8] Al-Sulaiman, F.A., Hamdullahpur, F., Dincer, I. Performance assessment of a novel system using parabolic trough solar collectors for combined cooling, heating, and power production. Renewable Energy 2012; 48:161-172.

[9] Marin, A., Untea, A., Grosu, L., Dobrovicescu, A., Queiros-Conde, D. Performanceevaluation of a combined organic Rankine cycle and an absorption refrigerationsystem. Termotehnica2013; 1: 81-90.

[10] Eisavi, B., Khalilarya, S., Chitsaz, A., Rosen, M.A. Thermodynamic analysis of a novelcombined cooling, heating and power system driven by solar energy.Applied Thermal Engineering 2018; 129: 1219-1229.

[11] Zhao, L., Zhang, Y., Deng, S., Ni, J., Xu, W., Maa, M., Lin, S., Yu, Z. Solar driven ORCbased CCHP: comparative performance analysis between sequential and parallel system configurations. Applied Thermal Enggineering2018; 131:696-706.

[12] Sharifishourabi, M., Chadegani, E.A. Performance assessment of a new organic Rankine cycle based multigeneration system integrated with a triple effect absorption system. Energy Convers Manage 2017; 150: 787-99.

[13] Gogoi, T.K., Saikia, S. Performance analysis of a solar heat driven organic rankine cycle and absorption cooling system. Thermal Science and Engineering Process 2019; 13: 100372.

[14] Cioccolanti, L., Hamedani, S.R., Villarini, M. Environmental and energy assessment of a small-scale solar Organic Rankine Cycle trigeneration system based on Compound Parabolic Collectors. Energy Convers Manage 2019; 198: 111829.

[15] Wang, S., Fu, Z. Thermodynamic and economic analysis of solar assisted CCHP-ORC system with DME as fuel. Energy Conversion and Management 2019; 186: 535-45.

[16] Gogoi, T.K., Hazarika, P. Comparative assessment of four novel solar based triple effect absorption refrigeration systems integrated with organic Rankine and Kalina cycles.Energy Conversion and Management2020;226:113561.

[17] Nondy, J., Gogoi, T.K. Comparative performance analysis of four different combined power and cooling systems integrated with a topping gas turbine plant.Energy Conversion and Management 2020;223:113242.

[18] Forristal, R. Heat transfer analysis and modelling of a parabolic trough solar receiver implemented in Engineering Solver Equation. National Renewable Energy Laboratory 2003, Golden, CO. (US); No. NREL/TP-550-34169.

[19] Technical Manuel: THERMINOL LT: Heat Transfer Fluids by SOLUTIA, Combined Heating and Cooling Liquid and Vapour Phase Heat Transfer Fluid in the temperature range from $-73^{\circ} \mathrm{C}$ to $315{ }^{\circ} \mathrm{C}$, Applied Chemistry, Creative solution.

[20] Modi, A., Pe'rez-Segarra, C.D. Thermocline thermal storage systems for concentrated solar power plants: One-dimensional numerical model and comparative analysis.Solar Energy 2014; 100: 84-93 
[21] Patek, J., Klomfar, J.A. computationally effective formulation of the thermodynamic properties of $\mathrm{LiBr}-\mathrm{H}_{2} \mathrm{O}$ solutions from 273 to $500 \mathrm{~K}$ over full composition range.International Journal of Refrigeration2006; 29(4): 566-78.

[22] Wagner, W., Cooper, J.R., Dittmann, A., Kijima, J., Kretzschmar, H.J., Kruse, A. IAPWS The Industrial Formulation, for the thermodynamic properties of waterand steam. Journal of Engineering for Gas Turbines and Power 2000; 122: 150-181. 